\title{
Esterco de ave como alternativa à adubação convencional de Brachiaria brizantha no estado de Rondônia (Zona da Mata) ${ }^{*}$
}

\author{
Lara, O.Q. ${ }^{1}$; Boni, D. ' ; Pichek, D.B. ' ; Matt, M.P. ' ; Souza, C.A. de ${ }^{1}$ e Ferreira, E. ${ }^{2}$
}

Universidade Federal de Rondônia (UNIR). Rolim de Moura. RO. Brasil.

${ }^{2}$ Departamento de Agronomia (UNIR). Rolim de Moura. RO. Brasil.

*Trabalho de conclusão de curso do primeiro autor.

\section{PALAVRAS ChAVE ADICIONAIS}

Adubação orgânica.

Resíduos animais.

Recuperação de pastagens.

\section{RESUMO}

Com o objetivo de avaliar a potencialidade do uso de esterco de poedeira, comparativamente à adubação convencional na produtividade da Brachiaria brizantha na Zona da Mata Rondoniense, foi desenvolvido um experimento na Fazenda Experimental da Universidade Federal de Rondônia, Campus Rolim de Moura. O delineamento experimental utilizado foi o de blocos casualizados, com três repetições. Os tratamentos constavam de adubação com seis doses de esterco de poedeira $\left(0,5,10,20,40\right.$ e $\left.80 \mathrm{tha}^{-1}\right)$ e adubação convencional com $120 \mathrm{~kg} \mathrm{ha}^{-1}$ de $\mathrm{N}, 100 \mathrm{~kg} \mathrm{ha}^{-1}$ de $\mathrm{P}_{2} \mathrm{O}_{5}$ e $60 \mathrm{~kg} \mathrm{ha}^{-1}$ de $\mathrm{K}_{2} \mathrm{O}$. Foram realizados sete cortes de avaliação no período de janeiro a julho de 2014, com intervalo de 25 dias entre cada corte e a uma altura de $15 \mathrm{~cm}$ do solo, com uma parcela útil de $0,25 \mathrm{~m}^{2}$. As dosagens de 40 e $80 \mathrm{tha}^{-1}$ de EP obtiveram as maiores produções de massa fresca e seca sendo superior estatisticamente a adubação convencional, enquanto as doses de 10 e $20 \mathrm{tha}^{-1} \mathrm{de}$

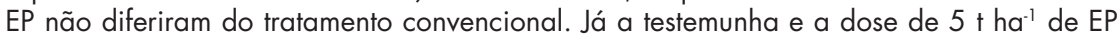
foram inferiores ao tratamento com adubação convencional. A produção de matéria seca da Brachiaria brizantha respondeu linearmente ao incremento de adubação orgânica, a maior produção acumulada durante as sete coletas foi estimada em $24720 \mathrm{~kg} \mathrm{ha}^{-1} \mathrm{MS}$ na dose de $80 \mathrm{t} \mathrm{ha}^{-1}$ de EP. Desta forma conclui-se que a adubação da Brachiaria brizantha com esterco de poedeira se mostrou eficiente comparativamente à adubação convencional quando utilizado dosagem igual ou superior a $10 \mathrm{tha}^{-1}$, nas condições edafoclímaticas da zona da mata rondoniense.

Hen manure as an alternative to Brachiaria brizantha conventional fertilization in the state of Rondônia (Zona da Mata)

\section{SUMMARY}

\section{ADDITIONAL KEYWORDS}

Organic fertilizer.

Animal waste.

Pasture recovery.

\section{INFORMACIÓN}

Cronología del artículo.

Recibido/Received: 9.3.2015

Aceptado/Accepted: 10.9.2015

On-line: 10.12 .2015

Correspondencia a los autores/Contact e-mail:

odair.queiroz.lara@hotmail.com
Aimed at studying the potential of the use of hen manure, in comparison to conventional fertilization in relation to the productivity of Brachiaria brizantha in the Zona da Mata of Rondônia, an experiment was carried out at the Experimental Farm of the Federal University of Rondônia, Campus Rolim de Moura. The implemented experimental design was a randomized complete block design with three replicates. The treatments consisted of fertilization with six hen manure rates $\left(0,5,10,20,40\right.$ and $\left.80+\mathrm{ha}^{-1}\right)$ and conventional fertilization with $120 \mathrm{~kg} \mathrm{ha}^{-1} \mathrm{~N}, 100 \mathrm{~kg} \mathrm{ha}^{-1}$ of $\mathrm{P}_{2} \mathrm{O}_{5}$ and $60 \mathrm{~kg} \mathrm{ha}^{-1}$ of $\mathrm{K}_{2} \mathrm{O}$. Seven evaluation cuts were made in the period from January to July 2014, leaving a 25-days interval between each cut and at a $15 \mathrm{~cm}$ from the ground height, with a floor portion of $0.25 \mathrm{~m}^{2}$. The dosages of 40 and $80 \mathrm{tha}^{-1} \mathrm{EP}$ which had the highest production of fresh mass and dry weight were statistically higher than the ones from conventional fertilization, while the doses of 10 and 20 tha ${ }^{-1}$ EP did not differ from the conventional treatment. Since the test sample and a dose of $5 \mathrm{tha}^{-1}$ of EP the production of dry matter in the Brachiaria brizantha linearly responded to the increase in the organic fertilizer, the highest cumulative production during the seven collections was estimated at $24720 \mathrm{~kg} \mathrm{ha}^{-1} \mathrm{MS}$ at a dose of $80 \mathrm{tha}^{-1} \mathrm{EP}$. Thus it is concluded that the fertilization of Brachiaria brizantha with hen manure proved to be efficient in comparison to conventional fertilization when an equable dosage or greater than $10+\mathrm{ha}^{-1}$ in the soil and climatic conditions of the forest area of Rondônia.

\section{INTRODUÇÃO}

O Brasil possui o segundo maior rebanho bovino do mundo com 211,2 milhões de cabeças. Rondônia possui um rebanho bovino de 12,2 milhões de cabeças sendo o sétimo maior rebanho no ranking nacional (IBGE, 2012). De acordo com a Anualpec (2009) aproximadamente $90 \%$ de todo o rebanho nacional são ali- mentados exclusivamente com pastagens. Segundo o censo agropecuário IBGE (2006), as áreas de pastagens ocupam no país 172,3 milhões de hectares, constituindo no principal uso da terra. Sendo que cerca de $70 \%$ desta área é constituída por pastagens cultivadas, a maior parte deles ocupada por gramíneas do gênero Brachiaria (Gimenes, 2010). 
No estado de Rondônia, de acordo com o IBGE (2006) as áreas de pastagens ocupam 5,0 milhões de hectares, entretanto, cerca de $40 \%$ das pastagens formadas no estado apresentam-se em diferentes estágios de degradação (Costa, 2006). Para a melhoria da criação de bovinos sob pastagens, faz-se necessário a recuperação dessas áreas. Entre as diversas formas de recuperação de pastagens existentes, uma delas é a fertilização, que pode ser realizada com uso de fontes minerais ou orgânicas (Silva, 2005).

Deste modo, uma alternativa para os pecuaristas seria a utilização dos resíduos provenientes da criação intensiva de galinhas poedeiras, denominado de esterco de poedeira, que é considerado fonte importante de nutrientes para os vegetais devido ao elevado teor de N (Figueroa et al., 2012). Além disso, a baixa relação C:N do esterco de aves (Santos et al., 2010) favorece a disponibilidade da maior parte dos nutrientes aplicados às plantas, em especial do $\mathrm{N}$, aspecto que, juntamente com o baixo preço e a alta oferta de esterco, tem motivado a utilização deste resíduo como fertilizante.

Outro fator que motivou a utilização desse resíduo na nutrição de plantas foi a proibição do seu uso na alimentação de ruminantes de acordo com a Instrução Normativa $n^{\circ}$ 15, de 17 de julho de 2001 do Ministério da Agricultura Pecuária e Abastecimento-MAPA. Sendo que este material necessita de uma destinação ambientalmente correta uma vez que, como todos os resíduos orgânicos, o descarte não pode ser aleatório no ambiente, e a falta de critérios e monitoramento pode levar à contaminação ambiental. Além do que, a utilização de resíduos de aviários em substituição aos fertilizantes químicos se torna de extrema importância para a implantação de um sistema sustentável, redução de uso das reservas finitas de adubos e de energia não renovável.

Lana et al. (2010) estudando a alteração da produtividade da Brachiaria decumbens com diferentes doses de cama de frango em comparação com a adubação convencional $\left(60,75\right.$ e $100 \mathrm{~kg} \mathrm{ha}^{-1}$ de $\mathrm{N}, \mathrm{P}_{2} \mathrm{O}_{5}$ e $\mathrm{K}_{2} \mathrm{O}$ respectivamente), não obtiveram diferença estatística no primeiro corte para a variável produção de matéria seca. Contudo, no segundo corte os tratamentos que receberam maiores doses de cama de frango (9,3 e 12,5 $\mathrm{t} \mathrm{ha}^{-1}$ ) apresentaram maior produtividade de MS, com incremento de $237 \%$ e $166 \%$ respectivamente para 9,3 e $12,5 \mathrm{t} \mathrm{ha}^{-1}$, em relação a forrageira adubada convencionalmente que obteve produção de $1606 \mathrm{~kg} \mathrm{ha}^{-1}$ de MS.

Desta forma, espera-se com a utilização deste resíduo o fornecimento de nutrientes para as plantas, e de matéria orgânica, que promoverá melhoria no sistema solo-planta. Além de tornar o esterco de poedeira uma alternativa para a substituição do fertilizante químico por uma fonte renovável. Diante disto, objetivou-se avaliar a potencialidade do uso de esterco de poedeira, comparativamente à adubação convencional na produtividade da Brachiaria brizantha na Zona da Mata Rondoniense.

\section{MATERIAL E MÉTODOS}

O estudo foi desenvolvido no período de novembro de 2013 a julho de 2014, na Fazenda Experimental da
Universidade Federal de Rondônia (UNIR), Rolim de Moura - RO, latitude $11^{\circ} 34^{\prime} \mathrm{S}$ e longitude $61^{\circ} 46^{\prime} \mathrm{W}$, a 240 m do nível do mar.

O solo da área experimental foi classificado como Latossolo Vermelho Amarelo Distrófico (EMBRAPA, 2013) e apresentava os seguintes atributos químicos e físicos nos primeiros $20 \mathrm{~cm}$ de profundidade: $\mathrm{pH}$ em água $=5,97$; matéria orgânica $=2,67 \mathrm{~g} \mathrm{dm}^{-3} ; \mathrm{P}=0,46 \mathrm{mg}$ $\mathrm{dm}^{-3} ; \mathrm{Na}=0,11 \mathrm{cmol}_{\mathrm{c}} \mathrm{dm}^{-3} ; \mathrm{K}=0,35 \mathrm{cmol}_{\mathrm{c}} \mathrm{dm}^{-3} ; \mathrm{Ca}=2,00$ $\mathrm{cmol}_{\mathrm{c}} \mathrm{dm}^{-3} ; \mathrm{Mg}=1,36 \mathrm{cmol}_{\mathrm{c}} \mathrm{dm}^{-3} ; \mathrm{Al}=0,30 \mathrm{cmol}_{\mathrm{c}} \mathrm{dm}^{-3}$; $\mathrm{H}+\mathrm{Al}=3,30 \mathrm{cmol}_{\mathrm{c}} \mathrm{dm}^{-3}$; areia $=32,2 \%$; silte $=8,9 \%$; argila $=58,9 \%$.

O clima da região é Aw segundo a classificação de Köppen sendo, portanto um clima equatorial com variação para o tropical quente e úmido, com estação seca bem definida (junho à setembro), temperatura mínima de $24^{\circ} \mathrm{C}$, máxima $32^{\circ} \mathrm{C}$, com precipitação anual média de $2250 \mathrm{~mm}^{2} \mathrm{ano}^{-1}$ e com umidade relativa do ar alta, em torno de $85 \%$ (Fernandes and Guimarães, 2002).

$\mathrm{O}$ esterco de poedeira (EP) utilizado no experimento foi adquirido em granja de galinhas poedeiras, sendo composto integralmente por fezes de aves poedeiras alimentadas com ração rica em macronutrientes e micronutrientes. Deste modo, para se evitar a queima da pastagem nas maiores dosagens de EP utilizadas no experimento e a possível ação de insetos presentes no adubo orgânico prejudicando a forrageira, foi necessário manter as fezes de galinhas poedeiras em processo de compostagem aeróbica por 50 dias antes da implantação do experimento, o resíduo foi umedecido até atingir a saturação e mantido coberto por plástico transparente e sendo revolvido três vezes por semana. Ao final desse período o EP possuía as seguintes características: $\mathrm{N}$ total $=3,1 \% ; \mathrm{P}_{2} \mathrm{O}_{5}$ total $=$ $10,1 \% ; \mathrm{K}_{2} \mathrm{O}$ solúvel em $\mathrm{H}_{2} \mathrm{O}=4,9 \%$; relação $\mathrm{C}: \mathrm{N}=9,3$ e teor de matéria seca de $37,5 \%$. Foram utilizados os métodos do ácido salicílico, método gravimétrico do Quimociac, método por fotometria de chama, respectivamente para as variáveis: $\mathrm{N}$ total, $\mathrm{P}_{2} \mathrm{O}_{5}$ total e $\mathrm{K}_{2} \mathrm{O}$ solúvel em $\mathrm{H}_{2} \mathrm{O}$. Para o cálculo da relação $\mathrm{C}: \mathrm{N}$, obtevese o teor de carbono orgânico pelo método volumétrico do dicromato de potássio e posteriormente realizou-se os cálculos de acordo com MAPA (2013). Para analisar a umidade foi seguido o método usualmente utilizado de secagem em estufa na temperatura de $105-110^{\circ} \mathrm{C}$ até peso constante.

O delineamento experimental utilizado foi o de blocos casualizados, com três repetições. Os tratamentos constavam de adubação com seis doses de esterco de poedeira $\left(0,5,10,20,40\right.$ e $\left.80 \mathrm{t} \mathrm{ha}^{-1}\right)$, sendo a dose zero considerada testemunha absoluta, adução convencional com $120 \mathrm{~kg} \mathrm{ha}^{-1}$ de N, $100 \mathrm{~kg} \mathrm{ha}^{-1}$ de $\mathrm{P}_{2} \mathrm{O}_{5}$ e $60 \mathrm{~kg} \mathrm{ha}^{-1}$ de $\mathrm{K}_{2} \mathrm{O}$ conforme a recomendação de adubação para manutenção de pastagens do Estado de Rondônia de acordo com Costa (2004). As unidades experimentais foram delimitadas por uma área de $9 \mathrm{~m}^{2}(3 \mathrm{~m} \times 3 \mathrm{~m})$, sendo utilizada como parcela útil um quadro experimental de $0,25 \mathrm{~m}^{2}$.

A área experimental inicialmente continha uma pastagem abandonada, cujo preparo foi realizado com um corte de uniformização da Brachiaria brizantha a uma altura de $15 \mathrm{~cm}$ do solo com o auxílio de roçadora 
costal. Após 25 dias do corte de uniformização foi realizado o corte de nivelamento seguido da implantação dos tratamentos.

O esterco de poedeira foi aplicado a lanço sem incorporação, nas parcelas referentes à adubação orgânica. Quanto à adubação química, utilizou-se como fonte de NPK, respectivamente uréia ( $45 \%$ de N), superfosfato simples ( $18 \%$ de $\mathrm{P}_{2} \mathrm{O}_{5}$ ) e cloreto de potássio (58\% de $\mathrm{K}_{2} \mathrm{O}$ ). As adubações com fósforo e potássio referentes ao tratamento com adubação convencional foram realizadas a lanço no mesmo dia em que se aplicou o adubo orgânico, sendo a adubação nitrogenada parcelada em seis aplicações durante o período das águas: uma logo após o corte de nivelamento e as demais imediatamente após os cinco primeiros cortes de avaliação.

Foram realizados sete cortes de avaliação no período de janeiro a julho de 2014, cada 25 dias. Os cortes eram realizados a uma altura de $15 \mathrm{~cm}$ do solo numa área de $0,25 \mathrm{~m}^{2}(0,5 \times 0,5 \mathrm{~m})$ no centro da parcela. $\mathrm{O}$ material vegetal coletado era adicionado em sacos plásticos identificados e encaminhado ao laboratório, onde foi realizada a pesagem para a determinação da massa fresca da forrageira, em seguida foram retiradas subamostras de cerca de $200 \mathrm{~g}$, acondicionada em sacos de papel e levadas a estufa de ventilação forçada a $65^{\circ} \mathrm{C}$ por 72 horas para determinação da massa seca.

Após a coleta dos dados todo o capim da área experimental recebeu um corte a uma altura de $15 \mathrm{~cm}$ do solo e em seguida todo o material vegetal era retirado da área, de maneira a simular o pastejo e evitar a liberação de nutrientes pela decomposição desse material.

As variáveis analisadas na forrageira foram o teor de matéria seca (\%MS), altura da forragem $(\mathrm{cm})$, produção de massa fresca (PMF) $\left(\mathrm{kg} \mathrm{ha}^{-1}\right)$, produção de massa seca (PMS) $\left(\mathrm{kg} \mathrm{ha}^{-1}\right)$ por corte e acumulada.

A altura da forrageira foi obtida medindo-se as plantas com uma trena, da base até a sua folha superior, em três pontos aleatórios dentro da parcela. A determinação da PMF foi feita pela extrapolação do peso fresco da forragem obtido na parcela útil, para hectare. A \%MS foi encontrada dividindo o peso seco pelo peso fresco da amostra e multiplicando-se por 100. A PMS foi obtida multiplicando-se a PMF pela \% MS da forragem. A PMF acumulada e PMS acumulada foram determinadas somando-se os valores obtidos em cada corte durante o período avaliado.

Foram empregados dois procedimentos para análise. O primeiro procedimento, considerado o padrão, no qual a comparação é realizada com as massas acumuladas da produção por parcela ao longo do tempo e adotou-se o seguinte modelo estatístico:

Onde,

$$
Y i j=\mu+\beta j+\tau i+\varepsilon i j
$$

Yij= valor total observado na parcela experimental do j-ésimo bloco que recebeu o i-ésimo tratamento; $\mu$ : média geral;

$\beta \mathbf{j}=$ efeito do j-ésimo bloco $[\mathrm{j}=1,2, \ldots, \mathrm{b}]$;

$\tau \mathbf{i}=$ efeito i-ésimo do tratamento $[\mathrm{i}=1,2, \ldots, \mathrm{t}]$; e

$\varepsilon i j=o$ erro aleatório, $\varepsilon i j \sim \operatorname{NID}(0, s 2)$.
Posteriormente, foram realizadas a análise de regressão das massas em função das doses de esterco de poedeira aplicadas e o teste de Dunnett entre as doses e a adubação NPK. Utilizou-se o software Assistat para realizar estas análises (Silva and Azevedo, 2002).

O segundo procedimento, realizado para este tipo de conjunto de dados, considera as medidas repetidas em uma mesma parcela ao longo dos cortes, e pode ser descrito como:

$$
Y i j k=\mu+\beta j+\tau i+\alpha k+(\tau \alpha) i k+\xi i j k
$$

em que,

Yijk= valor observado na parcela experimental do j-ésimo bloco que recebeu o i-ésimo tratamento no k-ésimo ano;

$\boldsymbol{\mu}=$ média geral;

$\beta \mathbf{j}=$ efeito do j-ésimo bloco $[\mathrm{j}=1,2, \ldots, \mathrm{b}]$;

$\tau \mathbf{i}=$ efeito $\mathrm{i}$-ésimo do tratamento $[\mathrm{i}=1,2, \ldots, \mathrm{t}]$;

$\alpha \mathbf{k}=$ efeito k-ésima da colheita $[\mathrm{k}=1,2, \ldots, \mathrm{c}]$;

$(\tau \alpha) \mathbf{i k}=$ efeito da interação entre o i-ésimo tratamento e a k-ésima colheita; e

そ̇ijk= o erro aleatório, $\varepsilon i j k \sim \mathrm{N}(0, \mathrm{~V})$.

Neste caso, V é a matriz de covariâncias adotada para modelar a dependências dos erros. Neste caso testou-se as seguintes matrizes de covariâncias: componentes de variância (padrão), auto-regressivo de primeira ordem, auto-regressivo com médias móveis, auto-regressivo heterogêneo de primeira ordem e simetria composta. Para identificação do modelo mais adequado, para cada variável, utilizou-se o critério de informação de akaike (AIC). Finalmente empregou-se o teste da máxima verossimilhança para verificar se havia efeito significativo entre ao ser adotar com menor AIC em relação ao modelo com matriz de componentes de variância. Deste modo, para apresentação dos resultados, para massa seca adotou-se a matriz de covariância auto-regressivo de primeira ordem $(p$-valor $<0,01)$ e para massa fresca auto-regressivo com médias móveis ( $\mathrm{p}$-valor $<0,01)$. Para estas análise empregou-se a função lme( ) do pacote NLME do software livre R (Pinheiro et al., 2014). Finalmente, realizou-se a análise de regressão para avaliar a produção em função dos cortes, com auxílio do software livre R (R Core Team, 2014).

\section{RESULTADOS E DISCUSSÃO}

Para a variável PMF acumulada houve diferença significativa $(\mathrm{p}<0,05)$, nas dosagens de 40 e $80 \mathrm{t} \mathrm{ha}^{-1} \mathrm{de}$ EP, com um incremento na produção de 48,7 e 84,4\%, respectivamente, comparando com a forragem adubada convencionalmente que produziu $71052,1 \mathrm{~kg} \mathrm{ha}^{-1} \mathrm{de}$ massa fresca acumulada. Nas dosagens de 10 e $20 \mathrm{t} \mathrm{ha}^{-1}$ de EP não houve diferença significativa em relação a adubação convencional na PMF acumulada (tabela I). Observa-se também diferença estatística da testemunha e da dose de $5 t^{\text {ha }}{ }^{-1}$ de EP em relação ao tratamento convencional, apresentando médias $43,7 \%$ e 33,0\% inferiores na PMF acumulada, respectivamente. $\mathrm{O}$ fato 
Tabela I. Produção de massa fresca (PMF) e produção de massa seca (PMS) acumulada e média, altura média e o teor de matéria seca (MS) médio dos sete cortes realizado na Brachiaria brizantha (Fresh mass production (FMP) and accumulated and average dry mass production (DMP), average height and dry matter content (SM) average value of the seven cuts performed in Brachiaria brizantha).

\begin{tabular}{lcccccc}
\hline Tratamentos & PMF acumulada $\left(\mathrm{kg} \mathrm{ha}^{-1}\right)$ & $\mathrm{PMS}$ acumulada $\left(\mathrm{kg} \mathrm{ha}^{-1}\right)$ & $\mathrm{PMF}$ média $\left(\mathrm{kg} \mathrm{ha}^{-1}\right)$ & $\mathrm{PMS}$ média $\left(\mathrm{kg} \mathrm{ha}^{-1}\right)$ & Altura média $(\mathrm{cm})$ & Teor de MS $(\%)$ \\
\hline Testemunha & $39974,13^{(-)}$ & $9670,40^{(-)}$ & $5710,59^{(-)}$ & $1381,48^{(-)}$ & $39,11^{\text {ns }}$ & $24,43^{(+)}$ \\
EP 5 & $47583,33^{(-)}$ & $11124,20^{(-)}$ & $6797,62^{(-)}$ & $1589,17^{(-)}$ & $43,72^{\text {ns }}$ & $23,39^{\text {ns }}$ \\
EP 10 & $58642,40^{\text {ns }}$ & $13104,67^{\text {ns }}$ & $8377,48^{\text {ns }}$ & $1872,09^{\text {ns }}$ & $45,76^{\text {ns }}$ & $22,36^{\text {ns }}$ \\
EP 20 & $79469,87^{\text {ns }}$ & $16770,27^{\text {ns }}$ & $11352,84^{\text {ns }}$ & $2395,75^{\text {ns }}$ & $51,09^{\text {ns }}$ & $21,13^{\text {ns }}$ \\
EP 40 & $105696,00^{(+)}$ & $20331,07^{(+)}$ & $15099,43^{(+)}$ & $2904,44^{(+)}$ & $62,40^{(+)}$ & $19,24^{(-)}$ \\
EP 80 & $130997,20^{(+)}$ & $23128,00^{(+)}$ & $18713,89^{(+)}$ & $3304,00^{(+)}$ & $73,81^{(+)}$ & $17,65^{(-)}$ \\
NPK & 71052,13 & 16018,93 & 10150,30 & 2288,42 & 49,48 & 22,58 \\
F & $* * *$ & $* *$ & $* 2$ & $* *$ \\
Média & 76202,15 & 15735,36 & 10886,02 & 2247,91 & 52,20 & 21,54 \\
CV $(\%)$ & 11,77 & 11,24 & 11,77 & 11,24 & 8,44 & 2,98
\end{tabular}

Médias seguidas por ${ }^{(+)}$foram superiores ao tratamento NPK, médias seguidas por ${ }^{(-)}$foram inferiores ao tratamento NPK e ${ }^{\text {ns }}$ médias não diferem do tratamento NPK em nível de $5 \%$ de probabilidade pelo teste Dunnett. ${ }^{* *}$ significativo ao nível de $1 \%$ de probabilidade $(p<0,01)$ pelo teste de F.

da dosagem de $5 \mathrm{t}$ ha $^{-1}$ EP ser inferior ao adubo convencional tem relação com a menor concentração de nitrogênio empregado neste tratamento, sendo que esta dose disponibilizou aproximadamente $58,1 \mathrm{~kg}$ ha ${ }^{-1}$ de N.

Em relação a PMS acumulada houve diferença estatística $(\mathrm{p}<0,05)$ nas dosagens de 40 e $80 \mathrm{t} \mathrm{ha}^{-1}$ de EP, com incremento de 26,9 e 44,4\% de produção em relação a pastagem adubada convencionalmente, respectivamente. As dosagens de 10 e 20 t ha $^{-1}$ não diferiram estatisticamente do tratamento convencional. Ocorreu efeito significativo da testemunha e da dose de $5 \mathrm{t} \mathrm{ha}^{-1}$ de EP, com médias 39,6\% e 30,5\% inferiores, em relação a produção de massa seca acumulada da forrageira que recebeu adubo convencional, respectivamente. A respeito Lima et al. (2007) avaliando a influência da adubação com cama de aviário em Brachiaria brizantha 'Marandu' verificaram que na dosagem de $5 \mathrm{t} \mathrm{ha}^{-1} \mathrm{a}$ adubação orgânica foi equivalente à adubação mineral, além de obter um incremento de 131,2\% de PMS do tratamento químico em relação a testemunha sem adubação. O mesmo autor relata que uma dose de 20 t ha- ${ }^{-1}$ de cama de frango proporcionou um incremento de $96,9 \%$ de PMS em relação ao tratamento com adubação mineral.

Para a altura observa-se diferença estatística $(\mathrm{p}<0,05)$ nas dosagens de 40 e $80 \mathrm{t} \mathrm{ha}^{-1}$ de EP, obteve-se um acréscimo na altura da forrageira de 12,92 e 24,33 $\mathrm{cm}$, respectivamente, comparado a adubação convencional. Nos demais tratamentos não houve diferença significativa $(\mathrm{p}<0,05)$ em relação ao tratamento convencional. Em relação ao teor de matéria seca da forrageira houve diferença estatística $(p<0,05)$ da testemunha em relação a pastagem adubada convencionalmente, observando teor de MS 8,2\% superior. Silva et al. (2012) testando a resposta do capim Marandú a aplicação de adubo químico e fontes de matéria orgânica obteve resultados semelhantes, justificando tal fato em função da maior lignificação dos tecidos na forrageira que não recebeu adubação e consequentemente menor teor de umidade e maior incremento na porcentagem de matéria seca. As doses de 5, 10 e 20 t ha $^{-1}$ de EP não diferiram estatisticamente do tratamento convencional. Houve efeito significativo nas dosagens de 40 e $80 \mathrm{tha}^{-1}$ de EP em relação a forrageira adubada convencionalmente, obtendo-se teores 17,3 e $27,9 \%$ inferiores, respectivamente.

A PMF acumulada e a PMF média no decorrer dos sete meses de avaliação são representadas por uma re-
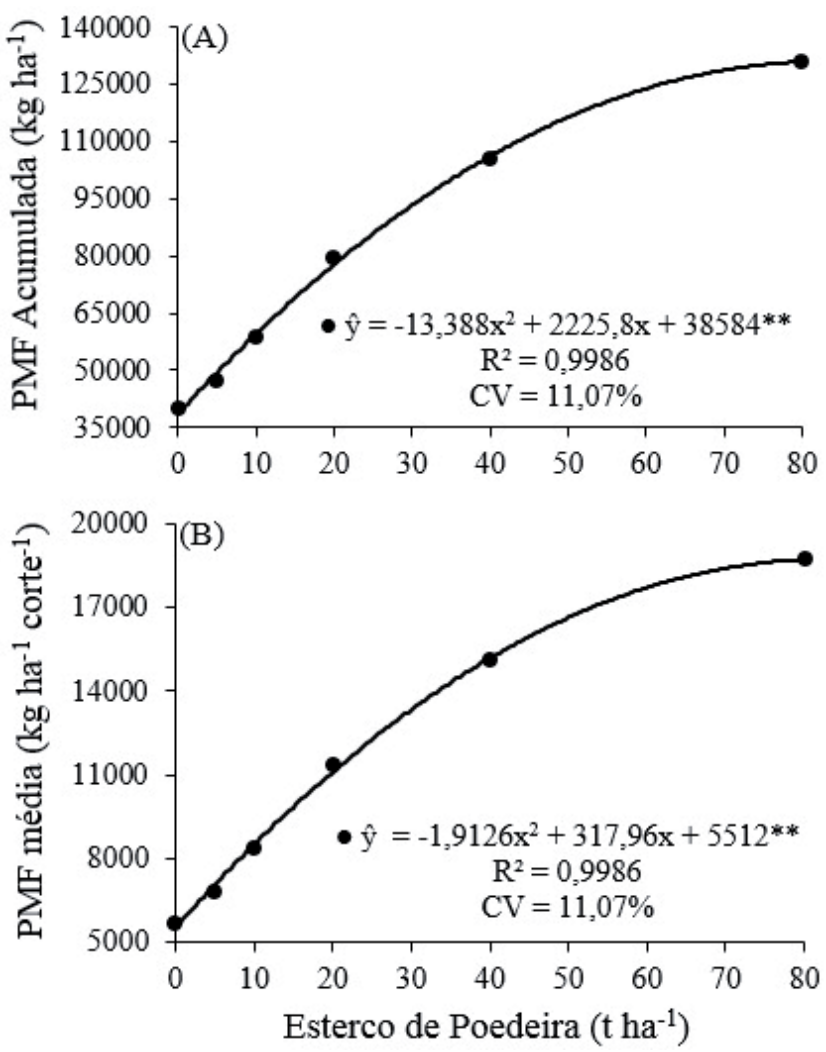

Figura 1. Efeito das doses de esterco de poedeira sobre a produção média por corte e acumulada de massa fresca (PMF) de Brachiaria brizantha. ${ }^{* *}$ Significativo pelo teste $\mathrm{F}$ ao nível de $1 \%$ de probabilidade $(p<0,01)($ Effect of hen manure on the average production per cut and accumulated fresh mass (FMP) of Brachiaria brizantha. ${ }^{* *} \mathrm{~F}$ test Significant at a $1 \%$ probability level at $1 \%(p<0.01))$. 

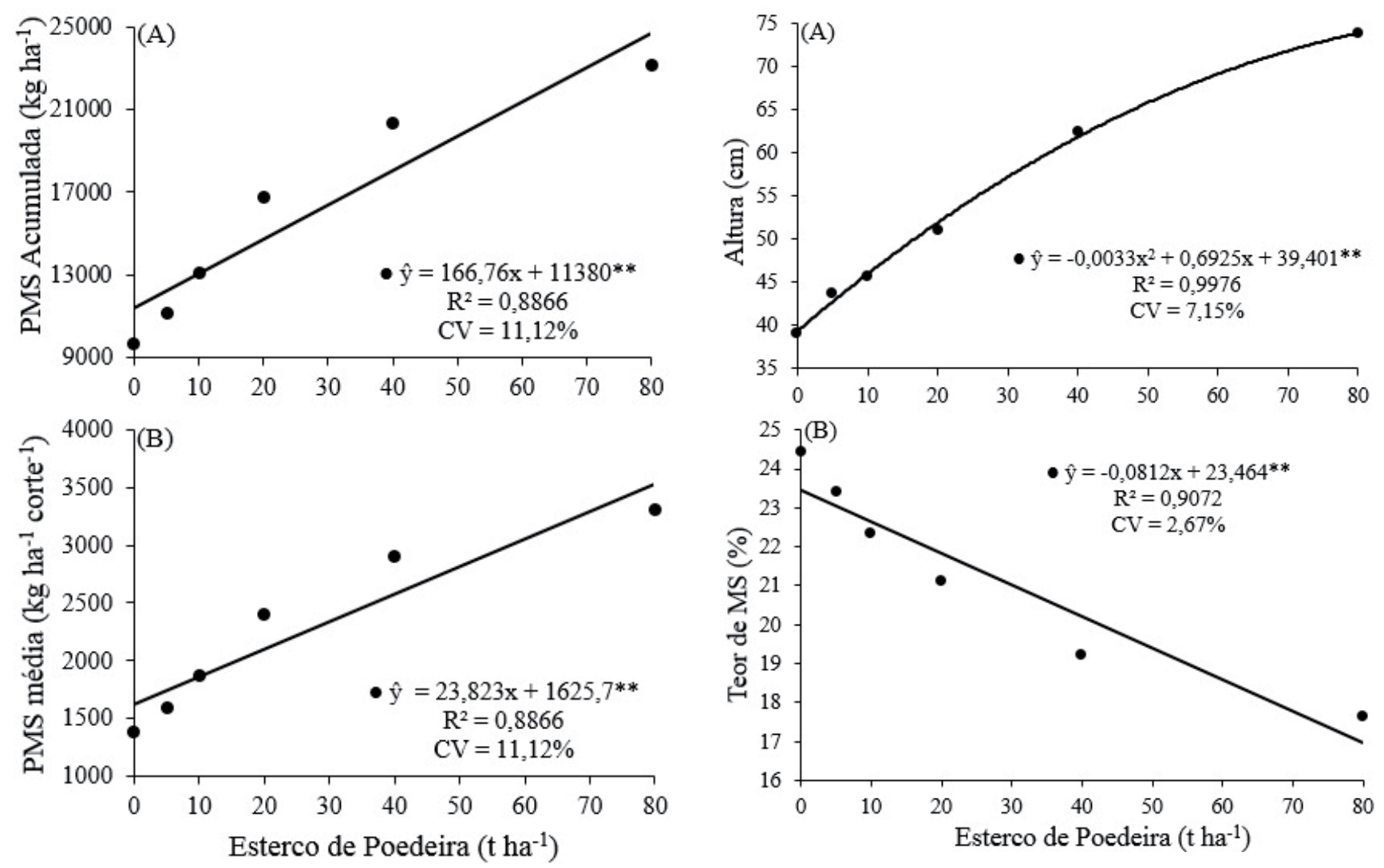

Figura 2. Efeito das doses de esterco de poedeira sobre a produção média por corte e acumulada de massa seca (PMS) de Brachiaria brizantha. **Significativo pelo teste $\mathrm{F}$ ao nível de $1 \%$ de probabilidade $(p<0,01)$ (Effect of hen manure on the average production per cut and accumulated dry mass (DMP) of Brachiaria brizantha. ${ }^{* *} \mathrm{~F}$ test Significant at a $1 \%$ probability level at $1 \%(p<0.01))$.

gressão quadrática em função das doses de $\operatorname{EP}(p<0,01)$, atingindo o ponto de máxima na dose de $80 \mathrm{t} \mathrm{ha}^{-1}$ de EP (figura 1A e B). As dosagens de 5, 10, 20, 40 e 80 t ha ${ }^{-1}$ de EP proporcionaram um incremento de $27,9 \%$; $54,2 \% ; 101,4 \% ; 175,2 \%$ e $239,4 \%$ respectivamente, em relação a testemunha que obteve uma produção estimada de $38584,2 \mathrm{~kg} \mathrm{ha}^{-1}$ e $5512,0 \mathrm{~kg} \mathrm{ha}^{-1}$ para PMF acumulada e PMF média dos cortes, respectivamente.

A PMS acumulada e PMS média no decorrer dos 185 dias de avaliação, foram influenciadas pela adubação orgânica e respondeu de forma linear e positivamente ao incremento nas doses de EP $(\mathrm{p}<0,01)$, sendo que a maior produção foi obtida aplicando-se $80 \mathrm{t} \mathrm{ha}^{-1}$ de EP (figura 2A e B). Desta forma, a aplicação de esterco de poedeira promoveu incrementos na PMS acumulada de 7,3\%; $14,6 \% ; 29,3 \% ; 58,6 \%$ e $117,2 \%$ para as doses de 5, 10, 20, 40 e $80 \mathrm{t} \mathrm{ha}^{-1}$ de EP, respectivamente, em relação a testemunha que obteve uma produção estimada de $11380,1 \mathrm{~kg} \mathrm{ha}^{-1}$ e 1625,7 $\mathrm{kg} \mathrm{ha}^{-1}$ para PMS acumulada e PMS média dos cortes, respectivamente. Resultados similares foram obtidos por Lima et al. (2007) observando o crescimento linear em função das doses de 5, 10, 15 e 20 t ha $^{-1}$ de cama de frango, com incrementos de 80,4\%; 160,8\%; $241,3 \%$ e $321,7 \%$, respectivamente, na produção de matéria seca acumulada de quatro cortes no período de setembro a junho, em relação a testemunha sem adubação. Araujo et al. (2009) testando compostos orgânicos semicurados

Figura 3. Efeito das doses de esterco de poedeira sobre os valores médios de altura e teor de matéria seca (MS) de Brachiaria brizantha. ${ }^{* *}$ Significativo pelo teste $\mathrm{F}$ ao nível de $1 \%(\mathrm{p}<0,01)$ de probabilidade (Effect of hen manure on the mean values of height and dry matter content (DM) of Brachiaria brizantha. ${ }^{* *} \mathrm{~F}$ test Significant at a $1 \%$ probability level at $1 \%(p<0.01))$.

na adubação de pastagem degradada de Brachiaria decumbens, observaram um incremento de $75,8 \%$ e $64,7 \%$ para as doses de 10 e $20 \mathrm{t} \mathrm{ha}^{-1}$ de composto de esterco de galinha, respectivamente, em relação a testemunha, obtendo efeito significativo.

Foi observado um efeito quadrático para a altura da forrageira com o incremento das doses de $\mathrm{EP}(\mathrm{p}<0,01)$, tendo ponto de máxima na dose de $80 \mathrm{t} \mathrm{ha}^{-1} \mathrm{de} \mathrm{EP}$, com uma altura estimada de 73,8 cm (figura 3A). Houve um incremento médio de $0,43 \mathrm{~cm}$ na altura das plantas para cada $1 \mathrm{t} \mathrm{ha}^{-1}$ de EP. Esses resultados têm relação com a quantidade de nitrogénio disponibilizado para a forrageira com as dosagens de esterco de poedeira. Segundo Martha Júnior (2003), o N metabolizado ativo, representado basicamente pelas enzimas, responde prontamente ao aumento do suprimento de $\mathrm{N}$ para planta, promovendo incrementos potenciais na fotossíntese e, consequentemente, no crescimento vegetal. Souza et al. (2013) ainda complementa que o uso de adubos nitrogenados nas pastagens permite a adoção de períodos de descanso mais curtos ou o emprego de maiores frequências de pastejo, garantido maior eficiência da área cultivada, sem a perda da estrutura e valor nutritivo do pasto.

Em estudos realizados no Tocantins com a Brachiaria brizantha 'Marandú', Silva et al. (2012) compararam adubações orgânicas e químicas, aos 42 dias após a 


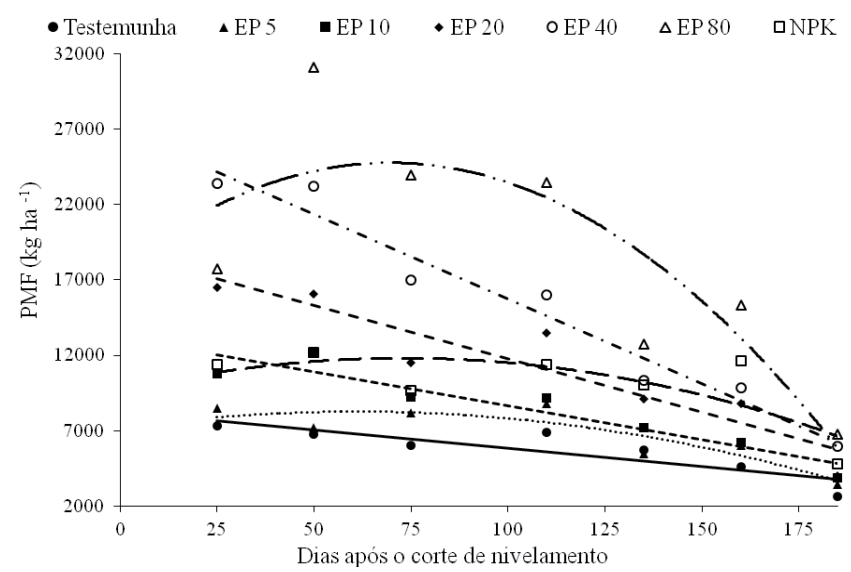

Figura 4. Efeito das doses de esterco de poedeira e adubação convencional sobre a produção de massa fresca de forragem (PMF) de Brachiaria brizantha, em função do tempo decorrido de 29 de dezembro de 2013 (dia 0) a 18 de julho de 2014 (dia 185). Equações de regressão na tabela II (Effect of hen manure and conventional fertilization on the forage fresh mass production (FMP) of Brachiaria brizantha, respecting to the period of time going from 29th December, 2013 (day 0) until 18th July, 2014 (day 185). Regression equations shown in table II).

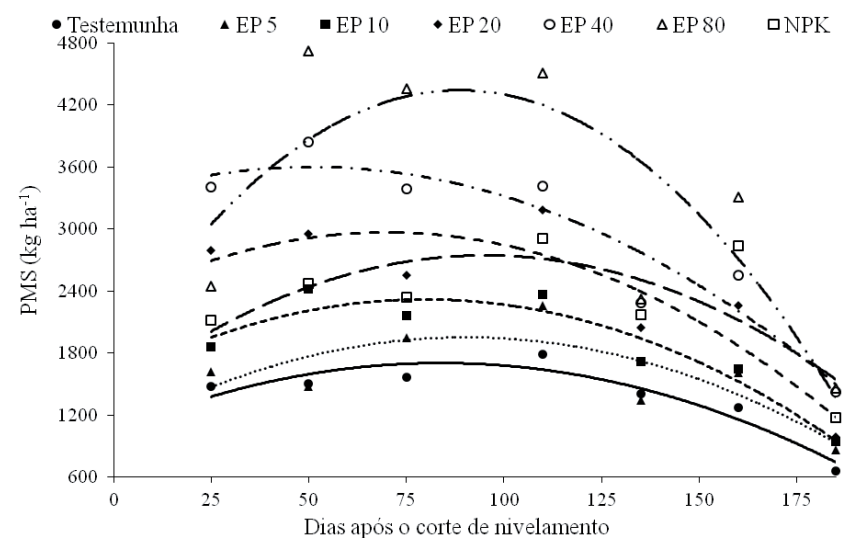

Figura 5. Efeito das doses de esterco de poedeira e adubação convencional sobre a produção de massa seca de forragem (PMS) de Brachiaria brizantha, em função do tempo decorrido de 29 de dezembro de 2013 (dia 0) a 18 de julho de 2014 (dia 185). Equações de regressão na tabela II (Effect of hen manure and conventional fertilization on the forage dry mass production (DM) of Brachiaria brizantha, respecting to the period of time going from 29th December, 2013 (day 0) until 18th July, 2014 (day 185). Regression equations shown in table II).

germinação obteve alturas de 52,9 cm e 168,6 cm, respectivamente para a testemunha sem adubação e o tratamento com cama de frango (56 t MS ha-1) durante o período das águas. Lisbôa et al. (2011) também obteve resultados positivos na adubação de Brachiaria brizantha 'Marandú' com cama de frango, relacionado os resultados ao teor de $\mathrm{N}$ presente no adubo orgânico.

Em relação ao teor de matéria seca observou-se efeito linear negativo em função das doses de EP $(p<0,05)$, obtendo-se o menor teor de MS na dose de $80 \mathrm{t} \mathrm{ha}^{-1}$ de EP, com porcentagem estimada de 16,9\% (figura 3B). Obteve-se valores estimados de 23,5\%, 23,1\%; 22,6\%; $21,8 \%$ e $20,2 \%$, respectivamente para as doses $0,5,10$, 20 e $40 \mathrm{t} \mathrm{ha}^{-1}$ de EP. Souza et al. (2013) obteve um efeito linear negativo testando doses de N no capim-Maran- dú, tendo teores estimados de $27,0 \%$; 25,8\%; 24,6\%; $23,4 \%$ e 22,2\% para as doses de $0,24,48,72$ e $96 \mathrm{~kg} \mathrm{ha}^{-1}$ corte $^{-1}$, respectivamente.

Segundo Corsi (1994) se o nitrogênio e outros fatores permitirem o crescimento da planta, a tendência é de utilização dos carboidratos disponíveis para a formação de células em vez de provocar o espessamento das paredes celulares pelo acúmulo desses carboidratos, de modo que as células produzidas sob estas condições tendem a ser grandes e de pouca espessura. Deste modo, com o suprimento da necessidade de nitrogênio da forrageira pelas maiores dosagens de esterco de poedeira, provavelmente tenha ocorrido um alongamento e aumento no volume celular, com maior acúmulo de solutos no vacúolo, desta forma ocorreu resultados inversos para a variável teor de matéria seca em relação à altura da forrageira e PMS, fato observado também por Silva et al. (2012) em experimentos com Brachiaria brizantha submetida a diferentes tipos de adubação orgânica e mineral.

Realizando a análise de regressão dos tratamentos em função dos dias de avaliação, observou-se uma queda na PMF (figura 4), tendo uma tendência linear negativa para os tratamentos testemunha e as doses de 10, 20 e $40 \mathrm{t} \mathrm{ha}^{-1}$ de EP, com uma queda da primeira para a sétima coleta de 50,3\%; 60,0\%; 66,35\% e 74,43\%, respectivamente. Já para os tratamentos EP 5, EP 80 e tratamento convencional observou-se um efeito quadrático, os mesmos promoveram incrementos na PMF do primeiro ao terceiro corte (75 dias de experimento), porem a partir daí houve uma queda atingindo valores de 3685,$0 ; 5874,0$ e $6636,2 \mathrm{~kg} \mathrm{ha}^{-1}$, respectivamente, no último corte (185 dias). A PMF da dose de $80 \mathrm{t} \mathrm{ha}^{-1}$ de EP foi 2,86 vezes maior do que a PMF da testemunha, na primeira coleta, e 1,54 maior na última coleta. Considerando a PMF do tratamento convencional em relação a testemunha, foram 1,42 e 1,75 para a primeira e última coleta, respectivamente.

Observou-se de maneira geral que as maiores dosagens de esterco de poedeira obtiveram produções iniciais de massa fresca de forragem superiores, reduzindo o percentual de diferença do primeiro para o último corte (tabela II). Todavia, as parcelas que receberam a maior quantidade de adubação orgânica apresentaram quedas mais significativas da PMF no decorrer do experimento. $\mathrm{O}$ tratamento NPK se comportou de forma mais estável durante os sete cortes realizados, possivelmente pelo fato de ter recebido adubação nitrogenada parcelada em seis vezes.

Analisando a produção de massa seca de forragem dos tratamentos em função do tempo de avaliação, obteve-se um efeito quadrático para todos os tratamentos (figura 5). A testemunha e as doses de 5, 10, 20 e 80 t ha-1 de EP atingiram a máxima produção no terceiro corte (75 dias de experimento), porem a partir daí houve uma queda atingindo valores de 734,8; 925,2; 959,1; 1185,4 e $1378,2 \mathrm{~kg} \mathrm{ha}^{-1}$, respectivamente, no último corte (185 dias). A dose de $40 \mathrm{t} \mathrm{ha}^{-1}$ de EP promoveu incremento na PMS do primeiro para o segundo corte (50 dias de experimento), a partir daí houve um declínio atingindo uma produção de $1491,4 \mathrm{~kg} \mathrm{ha}^{-1}$, na última coleta. A parcela que recebeu a adubação com NPK 
Tabela II. Modelos de regressão para as doses de esterco de poedeira (EP) e adubação convencional sobre a Brachiaria brizantha, nas variáveis produção de massa fresca (PMF) e produção de massa seca (PMS), em função do tempo (T), em dias, aos 25, 50,75, 110, 135, 160 e 185 dias após o corte de nivelamento, no decorrer de 24 de janeiro (dia 25) a 18 de julho de 2014 (dia 185) (Regression models for the hen manure (HM) and conventional fertilization on the Brachiaria brizantha, variables in fresh mass production (FMP) and dry mass production (DMP), as a function of time (T), on days $25,50,75$, $110,135,160$ and 185 days after the leveling cut, in the course of time from $24^{\text {th }}$ January (day 25) and $18^{\text {th }}$ July, 2014 (day 185)).

\begin{tabular}{|c|c|c|c|c|}
\hline Variável & Tratamentos & Equações & $\mathrm{R}^{2}$ & $\mathrm{CV}(\%)$ \\
\hline & 0 & $\hat{y}=8257,123-24,089 T^{* *}$ & 0,750 & 34,01 \\
\hline & EP 5 & $\hat{y}=7163,2+36,329 T-0,298 T^{2 *}$ & 0,783 & 16,92 \\
\hline & EP 10 & $\hat{y}=13135,875-45,012 T^{\star *}$ & 0,886 & 22,40 \\
\hline \multirow[t]{7}{*}{ PMF $\left(\mathrm{kg} \mathrm{ha}^{-1}\right)$} & EP 20 & $\hat{y}=18829,938-70,729 T^{* *}$ & 0,869 & 23,16 \\
\hline & EP 40 & $\hat{y}=26989,470-112,473 T^{* *}$ & 0,958 & 17,42 \\
\hline & EP 80 & $\hat{y}=17862+197,9 T-1,420 T^{2 * *}$ & 0,728 & 9,78 \\
\hline & NPK & $\hat{y}=9613+60,129 T-0,412 T^{2 * *}$ & 0,544 & 11,28 \\
\hline & 0 & $\hat{y}=1043,587+15,721 T-0,094 T^{2 *}$ & 0,896 & 29,14 \\
\hline & EP 5 & $\hat{y}=1025,9+20,545 \mathrm{~T}-0,114 \mathrm{~T}^{2 * *}$ & 0,641 & 17,71 \\
\hline & EP 10 & $\hat{y}=1535,6+19,639 T-0,123 T^{2 * *}$ & 0,894 & 19,73 \\
\hline \multirow{4}{*}{ PMS (kg ha-1) } & EP 20 & $\hat{y}=2304,652+18,925 T-0,135 T^{2 *}$ & 0,790 & 23,06 \\
\hline & EP 40 & $\hat{y}=3297,768+11,881 T-0,117 T^{2 \star}$ & 0,883 & 18,55 \\
\hline & EP 80 & $\hat{y}=1826,1+56,779 \mathrm{~T}-0,320 \mathrm{~T}^{2 * *}$ & 0,656 & 9,00 \\
\hline & NPK & $\hat{y}=1393,5+28,368 T-0,149 T^{2 * *}$ & 0,531 & 13,24 \\
\hline
\end{tabular}

*,**Significativo pelo teste $\mathrm{F}$ ao nível de $5 \%(p<0,05)$ e $1 \%(p<0,01)$ de probabilidade, respectivamente.

obteve incrementos na PMS até o quarto corte (110 dias de experimento), a partir deste corte a produção caiu atingindo $1542,0 \mathrm{~kg} \mathrm{ha}^{-1} \mathrm{com} 185$ dias de experimento. Cabe ressaltar que os decréscimos em produção com os últimos cortes podem ser atribuídos tanto a dinâmica de aproveitamento da planta, como também as condições estacionais.

Na primeira coleta, a PMS da dose de $80 \mathrm{t} \mathrm{ha}^{-1}$ de EP foi 2,17 vezes maior do que a PMS da testemunha, sendo que no último corte foi 1,87 vezes maior. O tratamento convencional obteve uma PMS 1,43 e 2,10 vezes maior em relação a produção da testemunha, no primeiro e último corte, respectivamente. Assim, as parcelas que receberam as maiores dosagens de adubação orgânica conseguiram manter uma produção de massa seca relativamente mais constante ao longo do tempo, diferente da produção de massa fresca que apresentou uma queda mais significativa, isso pode ser explicado pelo teor de matéria seca \%MS que aumentou ao longo do tempo, desta forma compensando a redução na PMF. A produção de massa seca do tratamento convencional se manteve relativamente constante ao longo do experimento e no último corte obteve a maior produção estimada.

De modo geral, observa-se que a maioria dos tratamentos, principalmente os que receberam adubação orgânica tem atingindo seu ponto de máxima de PMS na terceira coleta, sendo que no intervalo entre 21/02 (data da segunda coleta) e 19/03 (data da terceira coleta) ocorreu uma precipitação de $230 \mathrm{~mm}$, tendo o adubo orgânico uma baixa relação C:N, houve grande disponibilidade de nutrientes nos primeiros meses subsequentes a adubação, a partir daí houve redução da liberação de nutrientes do EP para a forrageira o que combinado com as condições ambientais acarretou essa queda nas variáveis analisadas.
Resultados similares foram encontrados por Costa et al. (2005) avaliando o efeito da estacionalidade na produção de matéria seca da Brachiaria brizantha 'Marandu', observou que nos meses de maio a setembro ocorreu uma baixa disponibilidade de forragem, sendo um terço daquela observada no período chuvoso, em virtude das condições climáticas, com baixas temperaturas, umidade do ar e precipitação, que não permitiram o desenvolvimento da forrageira. O mesmo autor relata que para uma alta produtividade de matéria seca, além da umidade, a planta necessita de temperaturas ideais para atingir sua produção máxima.

Segundo Mcwilliam (1978 apud Costa et al., 2005) a temperatura ideal para o crescimento das gramíneas de clima tropical varia de $30^{\circ} \mathrm{C}$ a $35^{\circ} \mathrm{C}$ enquanto que de $10^{\circ} \mathrm{C}$ a $15^{\circ} \mathrm{C}$ o crescimento é praticamente nulo, o que provocaria a estacionalidade na produção de forragem. Diante dito, fica evidente que os fatores climáticos influenciaram na redução da produção de forragem ao longo do experimento, sendo que houve uma redução da temperatura do ar nas últimas coletas, além da redução da precipitação, deste modo mesmo com a nutrição da planta, não houve a expressão do potencial produtivo da forrageira.

Considerando um consumo médio diário de $2,66 \mathrm{~kg}$ MS para cada $100 \mathrm{~kg}$ de peso vivo ou $12 \mathrm{~kg} \mathrm{MS} \mathrm{UA}^{-1}$ (UA - Unidade Animal, equivalente a $450 \mathrm{~kg}$ de peso vivo) (Aguiar et al., 2006), uma eficiência de pastejo de $50 \%$ e um período de descanso de 25 dias, isso significaria uma lotação de 2,4 UA ha- ${ }^{-1}$ no período das águas (janeiro) e 1,1 UA ha-1 no período seco (julho), no tratamento que não recebeu adubação. Enquanto na parcela que recebeu a dose de $80 \mathrm{t} \mathrm{ha}^{-1}$ de EP suportariam uma lotação de 4,1 UA ha-1 no período das águas (janeiro) e 2,4 UA ha-1 no período seco (julho). De acordo com Costa (2004) pastagens de Brachiaria brizantha bem formadas e manejadas apresentam uma capacidade de 
suporte de 1,5 a 2,5 UA ha ${ }^{-1}$ no período chuvoso e 1,0 a 1,5 UA ha-1 no período seco, dependendo do sistema de pastejo adotado e da disponibilidade de forragem. Isto reforça a importância da adubação nas pastagens de Brachiaria brizantha, para a otimização da pecuária a pasto.

Em relação aos aportes feitos, tem-se que a quantidade de $5 \mathrm{t} \mathrm{ha}^{-1}$ de EP contribuiu com o equivalente a $58 \mathrm{~kg}$ de $\mathrm{N}, 189 \mathrm{~kg}$ de $\mathrm{P}_{2} \mathrm{O}_{5}$ e $91 \mathrm{~kg}$ de $\mathrm{K}_{2} \mathrm{O}$, ou seja, níveis inferiores (a $\mathrm{N}$ ) ou mesmo superiores ( $\mathrm{P}$ e $\mathrm{K}$ ) dos nutrientes aportados com o uso da fonte industrial - NPK. Assim, a não equiparação da resposta nessas condições certamente está relacionada a dinâmica de imobilização/mineralização quanto aos teores de C:N. Níveis quantitativos que promoveram a resposta equiparada em significância estatística ao tratamento convencional só foi observada com doses de 10 e 20 t ha $^{-1}$ de EP.

Para as maiores doses, especialmente a de $80 \mathrm{t} \mathrm{ha}^{-1}$ de EP, foi aportado quantidades superiores de nutrientes (930 kg de $\mathrm{N}, 3030 \mathrm{~kg}$ de $\mathrm{P}_{2} \mathrm{O}_{5}$ e $1470 \mathrm{~kg}$ de $\mathrm{K}_{2} \mathrm{O}$ ) os quais podem promover respostas positivas para o próximo ciclo de pastejo e mesmo justificar o investimento na aplicação de EP.

De acordo com os dados apresentados, a utilização de $5 \mathrm{t} \mathrm{ha}^{-1}$ de EP proporciona uma produção inferior a adubação convencional, desta forma se o pecuarista optar em utilizá-la deve complementar os níveis de $\mathrm{N}$ presentes no esterco para obter produções satisfatórias e ainda elevar os níveis de matéria orgânica do solo. As doses de 10 e 20 t ha- ${ }^{-1}$ de EP obtiveram produções equivalentes a adubação convencional, sendo importante considerar os custos com transporte e distribuição para definir o tipo de adubação a se utilizar. Quanto as dosagens de 40 e 80 t ha-1 de EP proporcionaram produções superiores a forrageira adubada convencionalmente, entretanto deve considerar as relações custo-benefício para utilização destas doses, com o intuído de se aportar matéria orgânica ao solo. Além disso é importante a realização de mais estudos avaliando a composição bromatológica da forrageira em função da adição de doses de esterco de poedeira, para verificar se o ganho em produtividade é proporcional ao ganho em qualidade.

\section{CONCLUSÕES}

A adubação alternativa da Brachiaria brizantha com esterco de poedeira se mostrou eficiente comparativamente à adubação convencional quando utilizado dosagem igual ou superior a $10 \mathrm{t} \mathrm{ha}^{-1}$, nas condições edafoclímaticas da zona da mata rondoniense.

\section{BIBLIOGRAFIA}

Aguiar, A.D.; Santos, P.M. e Balsabore, M.A.A. 2006. Avaliação da influência da suplementação alimentar sobre a estimativa da taxa de lotação animal em pastagens. Embrapa Pecuária Sudeste. São Carlos. (Comunicado técnico, 64). 4 pp.

ANUALPEC: Anuário da pecuária brasileira. 2009. FNP Consultoria \& Comércio. Ed. Editora Argos. São Paulo. 392 pp.
Araujo, F.F.; Tiritan, C.S. e Oliveira. T.R. 2009. Compostos orgânicos semicurados na adubação de pastagem degradada de Brachiaria decumbens. Rev Ciên Agron Fortaleza, 40: 1-6.

Corsi, M. 1994. Adubação nitrogenada em pastagem. In: Peixoto, A.M.; Moura, J.C.; Faria, V.P. (Ed.). Pastagens: fundamentos da exploração racional. Fundação de Estudos Agrários Luiz de Queiroz. Piracicaba. pp.121-155.

Costa, K.A. de P.; Rosa, B.; Oliveira, I.P.; Custódio, D.P. e Silva, D.C. 2005. Efeito da estacionalidade na produção de matéria seca e composição bromatológica da Brachiaria brizantha 'Marandu'. Ciênc Anim Bras, 6: 187-193.

Costa, N. de, L. 2006. Adubação fosfatada na recuperação de pastagens degradadas de Brachiaria brizantha 'Marandu'. Agrosoft Brasil. http://www.agrosoft.org.br/agropag/19428.htm (20/02/2015).

Costa, N. de, L. 2004. Formação, manejo e recuperação de pastagens em Rondônia. Embrapa Rondônia. 219 pp.

EMBRAPA. 2013. Sistema brasileiro de classificação de solos. $3^{a}$ ed. Brasília. $353 \mathrm{pp}$.

Fernandes, L.C. e Guimarães, S.C.P. 2002. Atlas geoambiental de Rondônia. SEDAM. Secretaria do Estado do Desenvolvimento Ambiental. Governo do Estado de Rondònia. Porto Velho. Brasil.138 pp.

Figueroa, E.A.; Escosteguy, P.A.V. e Wiethölter, S. 2012. Dose de esterco de ave poedeira e suprimento de nitrogênio à cultura do trigo. Rev Bras Eng Agr Amb, 16: 714-720.

Gimenes, F.M.A. 2010. Produção e produtividade animal em capimmarandu submetido a estratégias de pastejo rotativo e adubação nitrogenada. Tese (Doutorado em Ciência Animal e Pastagens)-Escola Superior de Agricultura Luiz de Queiroz. Universidade de São Paulo. Piracicaba. 109 pp.

IBGE. Instituto Brasileiro de Geografia e Estatística. 2006. Censo Agropecuário - Brasil, 1970/2006. http://www.ibge.gov.br/home/ estatistica/economia/agropecuaria/censoagro/2006/tabela1_1. $\operatorname{pdf}(10 / 02 / 2015)$.

IBGE. Instituto Brasileiro de Geografia e Estatística. 2012. Efetivo dos rebanhos de grande porte em 31.12, segundo as Grandes Regiões e as Unidades da Federação - 2012. ftp://ftp.ibge.gov.br/Producao_Pecuaria/Producao_da_Pecuaria_Municipal/2012/tabelas_pdf/ tab03.pdf (10/02/2015).

Lana, R.M.Q.; Assis, D.F. de; Silva, A. de, A.; Lana, Â.M.Q.; Guimarães, E.C. e Borges, E.N. 2010. Alterações na produtividade e composição nutricional de uma pastagem após segundo ano de aplicação de diferentes doses de cama de frango. Bioscience J, 26: 249-256.

Lima, J.J. de; Mata, J. de D.V. da; Neto, R.P. e Scapim, C.A. 2007. Influência da adubação orgânica nas propriedades químicas de um Latossolo Vermelho distrófico e na produção de matéria seca de Brachiaria brizantha 'Marandu'. Acta Sci Agron Maringá, 29: 715-719.

Lisbôa, F.M.; Araujo Junior, L.M.; Mororó, D.L.; Miranda, P.B.; Knoechelmann, C.M. e Pause, A.G. da S. 2011 . Comportamento de Brachiaria brizantha cv. Marandu sob adubação orgânica. In: VII Congresso Brasileiro de Agroecologia, Fortaleza. Anais... Fortaleza. Cad Agroecol, 6: 1-5.

MAPA. Ministério da Agricultura Pecuária e Abastecimento. 2013. Manual de métodos analíticos oficiais para fertilizantes e corretivos - Brasília, 2013. http://sistemasweb.agricultura.gov.br/arquivosislegis/anexos/ arquivos/1204363.PDF (04/06/2015).

Martha Júnior, G.B. 2003. Produção de forragem e transformações do nitrogênio do fertilizante em pastagem irrigada de capim Tanzânia. 149f. Tese (Doutorado em Agronomia). Escola Superior de Agricultura Luiz de Queiroz. Universidade de São Paulo. Piracicaba.

Pinheiro, J.; Bates, D.; DebRoy, S.; Sarkar, D. e Core Team, R. 2014. _nlme: Linear and Nonlinear Mixed Effects Models_. R package version 3.1-118. http://CRAN.R-project.org/package=nlme (15/05/2015).

$R$ Core Team. 2014. R: A language and environment for statistical computing. R Foundation for Statistical Computing. Vienna. Austria. http://www.R-project.org/ (15/05/2015). 
Santos, F.G.; Escosteguy, P.A.V. e Rodrigues, L.B. 2010. Qualidade de esterco de ave poedeira submetido a dois tipos de tratamentos de compostagem. Rev Bras Eng Agríc Ambient, 14: 1101-1108.

Silva, A. de, A. 2005. Potencialidade da recuperação de pastagem de Brachiaria decumbens fertilizada com cama de aviário e fontes minerais. 152f. Dissertação (Mestrado Ciências Veterinárias). Faculdade de Medicina Veterinária. UFU. Uberlândia.

Silva, C.C.; Santos, A.C.; Silva, G.F.; Rocha, J.M.L.; Pires, C.C. e Oliveira, L.B.T. 2012. Resposta do capim Marandu (Brachiaria brizantha Stapf) a aplicação de NPK e fontes de matéria orgânica. Amazônia: Ciênc Desenv, 7: 43-57.

Silva, F.A.S. e Azevedo, C.A.V. 2002. Versão do programa computacional Assistat para o sistema operacional Windows. Rev Bras Prod Agroind, 4: 71-78.

Sousa, A.R.; Andrade, A.C.; Magalhães, J.A.; Mehl, H.U.; Rodrigues, B.H.N.; Silva, E.M.; Bitencourt, A.B.; Fogaça, F.H. dos S. e Costa, N. de L. 2013. Produtividade do Capim-Marandu sob diferentes doses de nitrogênio. PubVet, 7: 228. Art. 1510 
